\title{
DESAIN SARANA BAWA SKATEBOARD
}

\author{
Darius Shyafary \\ Staf Pengajar Program Studi Desain Produk, Jurusan Desain \\ Politeknik Negeri Samarinda \\ Aish Achyard Rahman \\ Mahasiswa Program Studi Desain Produk, Jurusan Desain \\ Politeknik Negeri Samarinda
}

\begin{abstract}
ABSTRAK
Skateboard adalah olahraga yang banyak diminati di luar negeri maupun Indonesia. Perkembangan olahraga skateboard di Indonesia masih tergolong sangat baru, Pada tahun 1980. beberapa orang sudah menekuni olahraga ini. Olahraga skateboard memerlukan papan skate yang memiliki roda dan truck pada bagian bawah papan. skateboarder memerlukan tools, baju ganti, dan air mineral pada saat bermain. Dan semua itu dibawa menggunakan sarana bawa khusus untukperlengkapan skateboard. Sarana bawa skateboard pada umumnya memiliki tempat menyimpan air mineral, baju ganti dan tools. Namun, nilai estetika pada sarana bawa tersebut kurang terlihat. Masih banyak sarana bawa skateboard yang memiliki grafis sangat sederhana, dan tidak memiliki unsur lokal Indonesia. Sarana bawa skateboard yang memiliki unsur lokal Indonesia diperlukan karena banyak nya komunitas skateboard di Indonesia yang memiliki ciri khas masing-masing. Sarana bawa ini ditujukan untuk komunitas skateboard di Indonesia. Dengan adanya ciri khas, para skateboarder sangat mudah dikenali dilihat dari style mereka. Gerakan kembali mencintai produk Indonesia juga sudah dilakukan para anak muda Indonesia agar bangga dengan produk buatan negeri sendiri.

Kata kunci: Skateboard, sarana bawa, etnik Indonesia.
\end{abstract}

\begin{abstract}
Skateboard is a sports are much in demand abroad as well as Indonesia. The development of the sport of skateboarding in Indonesia is newest, In 1980. some people already pursue this sport. Skateboard sports requires that had wheels and a truck at the bottom of the board. skateboarder require tools, a change of clothes, and mineral water at the time of play. And all of that was taken using a special tool to bring skateboarding equipment. Bag of skateboarding in general have a place to save mineral water, a change of clothes and tools of skateboard. But, The aesthetic value on the means that take less visible. There are still many bag of skateboard that has a very simple graphic, and does not have a local culture of Indonesia. Bag of skateboard that has elements of Indonesian local because of its many skateboard community in Indonesia which has the characteristic of each. This bag is intended for the skateboard community in Indonesia. With the characteristic, the skateboarder very easily recognizable views of their style. "support your local product" has also been done by young people in Indonesia to be proud of the product of their own country.
\end{abstract}

Keyword: skateboard, skatebag, Indonesian Ethnic 24 
Vol. 3, No. 2, April 2016

\section{Pendahuluan}

Skateboard adalah olahraga yang banyak diminati di luar negeri maupun Indonesia. Perkembangan olahraga skateboard di Indonesia masih tergolong baru, Pada tahun 1980, beberapa orang sudah menekuni olahraga ini. Peminatnya semakin banyak sejalan meskipun sebenarnya tidak pernah diadakan kejuaraan skateboard di Indonesia.

Peminat olahraga skateboard di Indonesia semakin besar dengan dibuatnya skatepark di kota kota di indonesia. Biasanya terdapat komunitas skateboard di setiap kota yang memiliki skatepark. Jumlah skatepark yang sering dipakai menjadi turnamen di indonesia yaitu berjumlah 14 skatepark. Penggiat skateboard di Indonesia juga memiliki hari penting yang jatuh setiap tanggal 21 juni. Pada tanggal 21 juni para skateboarder mengelilingi kota mereka dengan menggunakan skateboard dan berakhir dengan turnamen.

Gaya hidup skateboarder kental dengan aspek aktualisasi diri untuk menunjukkan identitas mereka terbukti dengan video skateboard yang berjudul "pretty sweet" yang merekrut banyak skaterboarder dengan style yang khas. Kelompok skateboarder dengan ciri khas tertentu sudah cukup banyak, seperti contohnya reggae Skateboard yang memiliki warna warna khusus pada aksesoris Skateboard yang mereka pakai seperti tas, baju dan sepatu juga papan pada Skateboard mereka. Tidak hanya Reggae, Punk skateboard dan gangsta skateboard pun sudah memiliki gaya tersendiri dalam hal style sebagai cara untuk memperlihatkan identitas mereka.

Perkembangan style skateboarder di Indonesia semakin berkembang dengan adanya skateshop yang menjual barangbarang perlengkapan skateboard. Saat ini sering muncul produk modern dengan sentuhan lokal. Salah satunya yaitu sepatu merk terkenal seperti DC yang memasukkan unsur lokal seperti batik Kalimantan pada sepatunya, Snapback atau topi dengan batik pada grafisnya, baju kaos dan celana dalam yang terkena sentuhan lokal seperti batik Indonesia. Hal tersebut muncul sebagai akibat dari gerakan kembali mencintai produk Indonesia

Kecintaan terhadap budaya lokal membuat mereka memasukkan unsur lokal seperti batik pada produk skate tersebut. Dengan adanya masukan unsur lokal ke dalam skateboard akan membuat budaya lokal semakin dikenal pada olahraga ini. Skateboarder di indonesia sudah ada yang memasukkan sentuhan lokal ke produk mereka seperti deck atau papan skateboard yang memiliki grafis Ondel-Ondel khas Jakarta, Batik Indonesia, dan unsur lokal lainnya. Secara ideologi para skateboarder sekarang sudah sadar dan mulai bergerak untuk ikut serta dalam gerakan nasionalisme untuk mendukung produk skateboard lokal yang memiliki unsur Indonesia dalam produk tersebut.

Baju, papan skateboard, snapback dan sepatu sudah ada yang memiliki unsur budaya lokal Indonesia. Tetapi, untuk sarana bawa seperti skateboard belum ada. Sehingga peluang untuk menciptakan suatu sarana bawa dengan unsur budaya lokal itu terbuka lebar. 
Darius Shyafary, Aish Achyard Rahman, Desain Sarana Bawa Skateboard

Tabel 1. Aktivitas dan Kebutuhan

\begin{tabular}{|l|l|l|}
\hline No. & \multicolumn{1}{|c|}{ Aktivitas } & \multicolumn{1}{|c|}{ Kebutuhan } \\
\hline 1. & $\begin{array}{l}\text { Membawa Skateboard (papan } \\
\text { luncur) ketempat tujuan }\end{array}$ & Ransel atau skatebag \\
\hline 2. & Menyimpan peralatan Skateboard & $\begin{array}{l}\text { Tempat atau kantung wadah } \\
\text { penyimpananskateboard. } \\
\text { Tempat atau kantong botol minum }\end{array}$ \\
\hline 3. & Membawa baju ganti dan air mineral & Lubang roda skateboard. \\
\hline 4. & Memperlihatkan roda & Tali gendongan / tas ransel \\
\hline 5. & Menggendong tas & Tempat tools \\
\hline 6. & Meletakkan tools & Gantungan helm skate \\
\hline 7. & Membawa helm skate & $\begin{array}{l}\text { Tempat menyimpan pelindung siku dan } \\
\text { lutut }\end{array}$ \\
\hline 8. & Membawa pelindung siku dan lutut \\
\hline
\end{tabular}

Berdasarkan analisis aktivitas dan kebutuhan yang terdapat pada tabel 1 di atas, maka telah didapatkan kesimpulan mengenai komponen-komponen apa saja yang harus ada dalam produk. Berikut fasilitas yang terdapat pada produk ialah: (1) Memiliki gendongan yang nyaman saat digunakan, (2) Memiliki tempat penyimpanan peralatan, (3) Memiliki kantong tempat menyimpan baju, (4) Memiliki kantong untuk menaruh air mineral atau air minum, (5) Memiliki tali sling agar tas dapat digendong, (6) Memiliki tempat untuk menyimpan tools, (7) Memiliki gantungan untuk helm skate, (8) Memiliki tempat untuk menyimpan pelindung siku dan lutut.

Analisis ergonomi untuk mengetahui produk apakah sudah aman dan nyaman ketika digunakan. Analisis ergonomi juga bisa untuk menyesuaikan suasana kerja dengan aktivitas manusia di lingkungannya. Produk sarana bawa skateboard ini harus mengangkut beban yang besar tetapi tidak terlalu berat. Menggangkat beban yang terlalu berat dapat menimbulkan rasa kram pada bagian bahu dan punggung.

Analisis anthropometri digunakan untuk mengukur kenyamanan dari sebuah produk. Dengan adanya kenyamanan dalam sebuah produk maka produk tersebut sudah bisa di produksi, jika sebuah produk tidak nyaman digunakan maka produk tersebut gagal dan tidak bisa di produksi.

Analisis juga dilakukan untuk mendapatkan susunan tiap-tiap komponen atau fasilitas yang akan diterapkan kedalam produk.

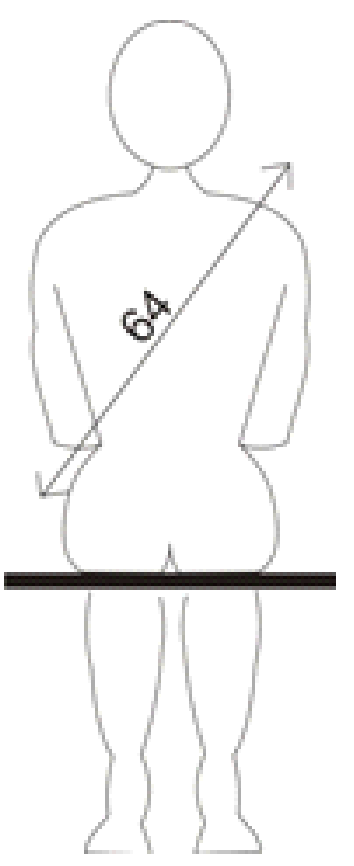

Gambar 1. panjang tali sling rata rata 
Vol. 3, No. 2, April 2016

Berikut adalah data anthropometri yang akan digunakan:

1. Menentukan tinggi tas diperoleh dari ukuran papan skateboard tersebut. yaitu $85 \mathrm{~cm}$.

2. Menentukan lebar tas diperoleh dari ukuran papan skateboard. Panjang dan lebar pada tas terfokus pada panjang dan lebar dari papan skateboard. tinggi bahu dan lebar bahu digunakan untuk menentukan panjang tali minimal, yaitu $21 \mathrm{~cm}$.

3. Menentukan panjang tali webbing pada tas dengan cara melakukan survey kepada 30 orang yang memiliki tinggi badan, berat badan, panjang punggung dan lebar punggung yang berbeda. Setelah mendapatkan rata rata, di peroleh hasil yaitu 63,2 cm dan dibulatkan menjadi $64 \mathrm{~cm}$.

Analisis konfigurasi dilakukan untuk mendapatkan susunan atau konfigurasi dari tiap-tiap komponen yang terdapat pada produk. Dari beberapa alternatif konfigurasi yang disertai analisis kesesuian, terpilih gambaran konfigurasi produk seperti yang ditunjukkan gambar 2.
Pada alternatif konfigurasi terpilih pada gambar 2, memiliki 3 kantung, tempat mnggantung helm dan tempat menyimpan pelindung siku dan lutut. konfigurasi ini memiliki posisi kantung yang lebih ringkas dan tidak memakan banyak space.

Analisis sistem dilakukan agar dapat menemukan sistem yang tepat untuk diaplikasikan pada produk. Berikut merupakan sistem yang diaplikasikan pada produk setelah dilakukan analisis pada kegiatan sebelumnya. Yaitu:

1. Jahitan merupakan suatu proses manual ataupun dengan menggunakan mesin untuk menyatukan maupun menyambung antar potongan kain sehingga menjadi suatu bentuk tertentu mengikuti pola dengan menggunakan benang dan jarum. Jahitan pada tas ini terletak pada bagian sisi samping tas, kantung dan resleting.

2. Sambungan Ladderlock buckles Sistem sambungan ini biasa ditemukan pada tali kit yang menghubungkan antara dua bagian tali yang terpisah. Ladderlock buckles terletak pada bagian tali sling.

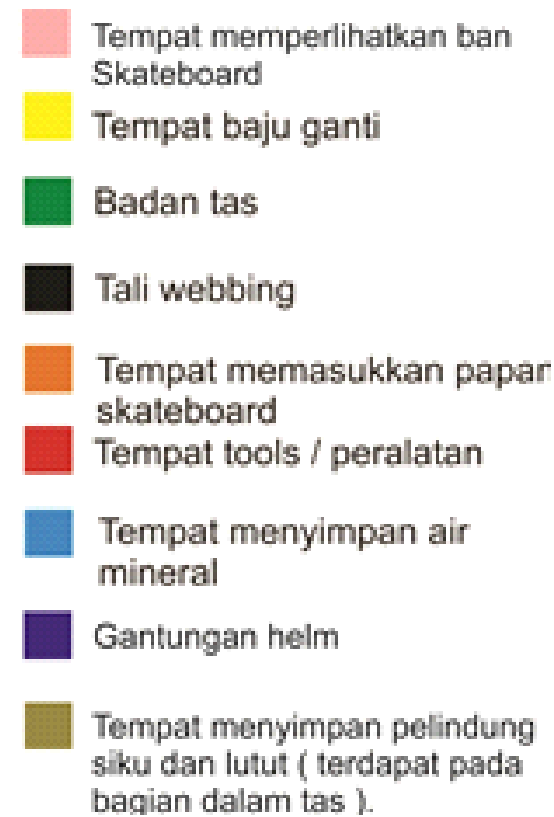

Gambar 2 Alternatif konfigurasi 
Darius Shyafary, Aish Achyard Rahman, Desain Sarana Bawa Skateboard

Digunakan pada tali sling agar pengguna dapat memanjangkan dan memperpendek tali sling sesuai dengan keinginan pengguna.

3. Sistem Kuncian Side release buckles, berfungsi sebagai penghubung dan pengunci. Perbedaannya adalah sistem ini memungkinkan tali untuk dipisah dan disatukan kembali. Terletak pada bagian tali sling agar pengguna dapat melepas dan memasang tali dengan mudah.

4. Resleting juga berfungsi sebagai buka tutup pada kantung yang terdapat pada bagian tas. Terletak pada bagian atas tas untuk memasukkan dan mengeluarkan papan skateboard.

5. Sistem sambungan stapler, digunakan untuk bagian penutupan atau kuncian akhir anyaman agar anyaman tidak terlepas.

6. Untuk sambungan rangka yang digunakan adalah sambungan rangka sudut-menyudut yang digunakan untuk bagian sambungan di sudut produk dan sambungan $\mathrm{T}$ atau siku yang digunakan untuk penghubung kerangka lainnya agar kokoh. Sambungan ini biasanya dhubungkan pada bagian tengah kerangka, sehingga menyerupai huruf $\mathrm{T}$. Rangka rotan berfungsi sebagai casing dari tas skateboard ini agar rotan dapat menopang beban dari tas ini dengan kuat.

7. Anyaman rotan. Anyaman digunakan untuk membawa papan skateboard dan perlengkapan yang membutuhkan anyaman yang kuat dan juga menyesuaikan keinginan pasar: Berdasarkan analisis yang telah dilakukan maka anyaman yang terpilih untuk diaplikasikan pada produk sarana bawa skateboard adalah finishing anyaman yang menggunakan rotan fitrit.

Analisis material dilakukan agar dapat menemukan material yang tepat untuk diaplikasikan pada produk. Berikut material yang akan diaplikasikan pada produk, yaitu:
1. Stretch denim, adalah kain denim yang dicampur dengan bahan elastis yaitu spandex. Porsinya tidak banyak, yaitu sekitar dua hingga tiga persen saja. Bahan elastis ini membuat kain denimnya menjadi lebih lentur, sehingga membuat bisa bergerak dengan leluasa. Jenis denim ini terbilang baru, dan sering digunakan untuk membuat celana jeans, terutama jeans wanita. Kain ini digunakan sebagai bahan utama pada produk, Karena bahan yang bertekstur lembut dan lentur ini membuat produk bertahan lama atau awet.

2. Kain Interlining atau kain keras, adalah kain yang digunakan untuk pengeras atau melapisi pada bagian-bagian tertentu sehingga membantu membuntuk siluet pakaian. Jenis kain interlining ada yang mempunyai lem atau perekat sehingga kain menjadi keras dan ada yang tidak berperekat. Interlining sering digunakan pada bagian-bagian pakaian seperti lingkar leher, kerah, belahan tengah muka, ujung bawah pakaian, bagian pundak pada jas, pinggang dan lain-lain.

3. Anyaman rotan, adalah material yang terbuat dari kayu rotan yang di anyam. Anyaman rotan di aplikasikan pada produk sebagai rangka dasar sekaligus menjadi hiasan dari sarana bawa skateboard ini. Selain menjadi penahan pada sarana bawa ini, anyaman ini juga berfungsi sebagai salah satu upaya untuk menyatukan unsur budaya lokal dan modern.

4. Foam atau busa. Busa akan digunakan pada bagian punggung karena memberikan efek nyaman saat ransel digunakan.

5. Tenun Khas, merupakan teknik dalam pembuatan kain yang dibuat dengan prinsip yang sederhana, yaitu dengan menggabungkan benang secara memanjang 
Vol. 3, No. 2, April 2016

dan melintang. Dengan kata lain

bersilangnya antara benang lusi dan pakan

secara bergantian. Kain tenun biasanya

terbuat dari serat kayu, kapas, sutra, dan

lainnya.

Analisis bentuk digunakan untuk memilih bentuk jenis apa yang akan diaplikasikan pada produk. Pendekatan bentuk yang digunakan pada Desain Sarana Bawa Skateboard adalah gaya desainPost Modern.. Lebih tepatnya yaitu gaya desain Ekletik. Gaya desain ekletik adalah gaya desain yang mencampur gaya etnik dan modern. Seperti yang di aplikasikan pada sarana bawa ini yaitu material tas modern dan anyaman. Material tas modern yaitu kain Jeans, kain tenun dan anyaman yang disatu padukan. Bentuk Ekletik dipilih sesuai karakteristik para skateboarder yaitu bebas, tidak mau di atur dan anti mapan. Maka dari itu, gaya desain Ekletik ini sangat cocok di aplikasikan pada sarana bawa skateboard ini. Analisis warna digunakan untuk menentukan warna yang akan diaplikasikan pada produk. Berdasarkan analisis yang telah dilakukan maka warna yang terpilih untuk diaplikasikan pada produk sarana bawa skateboard adalah kombinasi antara warna netral dan warna lain, untuk bagian tasnya yaitu warna coklat, karena cocok dengan warna alami dari anyaman rotan.

Grafis pada sarana bawa ini yaitu batik khas Indonesia dan tambahan kain tenun bertujuan untuk mengangkat budaya lokal ke produk modern.

Langkah awal mendesain dilakukan dengan membuat sketsa desain awal. Desain awal ini terdiri dari bebrapa alternatif, kemudian alternatif alternatif ini dianalisis kelebihan dan kekurangannya sampai terpilih alternatif yang diinginkan. Dari alternatif terpilih ini dikembangkan lagi, menjadi beberapa desain pengembangan, yang dilengkapi dengan Selanjutnya dilakukan sketsa awal yang terdiri dari beberapa alternatif desain. Alternatif alternatif desain tersebut kemudian dianalisis sehingga terpilih satu desain terpilih yang sudah final. Desain final ini dijabarkan dalam bentuk gambar kerja sehingga bisa diproduksi. Gambar kerja yang dijabarkan dalam bentuk gambar presentasi, gambar isometri, gambar teknik, gambar potongan, gambar urai, gambar detail. Selanjutnya gambar kerja diproduksi prototipenya untuk dievaluasi kelayakan produk. Setelah didapatkan hasil sesuai kebutuhan dan persyaratan sesuai spesifikasi teknis, desain masuk tahap produksi massal.

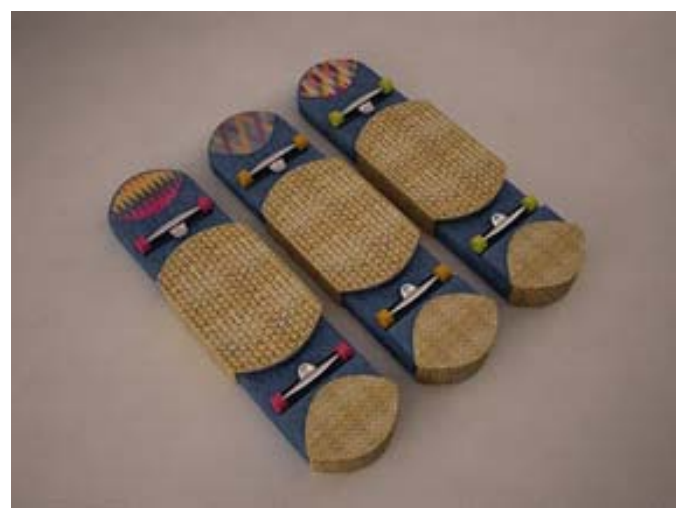

Gambar 3. Desain akhir 
Darius Shyafary, Aish Achyard Rahman, Desain Sarana Bawa Skateboard

\section{Kesimpulan}

Simpulan dari hasil perancangan

"Desain sarana bawa Skateboard" ialah sebagai sarana untuk mempermudah membawa papan Skateboard beserta baju ganti dan tools, karena tas ini memiliki tempat khusus untuk menyimpan baju ganti dan tools. Tas tersebut didesain dengan sistem yang sederhana dan mudah saat dioperasionalkan. Warna yang diaplikasikan pada produk menggunakan warna alami dari kain jeans dan warna alami dari anyaman rotan. Tas tersebut dilengkapi aksen tenun Bali dan aksesoris berupa anyaman rotan bertujuan untuk memperlihatkan unsur budaya lokal pada tas ini.

Saran yang dapat saya berikan adalah tas ini masih bisa dikembangkan menjadi lebih sempurna lagi, Di karena cara memasukkan dan mengeluarkan papan skateboard masih sedikit sulit. Kenyamanan juga kurang dikarenakan anyaman rotan pada bagian tas yang keras kurang nyaman saat dipakai di bagian punggung. 


\section{DAFTAR RUJUKAN}

Kurniaputri, Dewanti. 2008. Analisis segmentasi. FE-UI, 2008

Martono,et.al. 2011. Sari Hasil Penelitian Rotan Jasni. Melalui www.dephut.go.id [24/01/ 2012]

Sudiajeng, Lilik. HA. Bakri.Tawarka.(2004).Ergonomi untuk keselamatan kerja, kesehatan dan produktivitas.UNIBA PRESS. Surakarta.

Tim Penyusun Kamus Pembinaan dan Pengembangan Bahasa (3nd ed). (2005). Kamus Besar Bahasa Indonesia. Jakarta: Balai Pustaka.

. 2013. Bagian - bagian Skateboard. (27Maret 2016)

https://mjsidik.wordpress.com/2013/02/27/bagian-bagian-skateboard/

2013. Bagian - Sejarah dan perkembangan Skateboard di Indonesia. (28 Maret 2016)

www.planetsurfonline.com/index.php/blog/sejarah-dan...skateboard-di-indonesia/95

.2015. Daftar Skatepark di Indonesia(15Maret 2016)

http://busyraoryza.com/2015/03/07/skaterpark-di-indonesia-dan-luar-negeri/

. 2015. Gaya hidup Skateboarder. (28 Maret 2016)

www.garudacitizen.com

. 2015. Gerakan aku cinta produk Indonesia. (17Maret 2016)

http://www.kaskus.co.id/thread/55add4d01854f7153a8b4570/dukung-produk-buatanasli-indonesia/

2013. Macam - macam tas tradisional Indonesia. (28 Maret 2016)

www.indonesiakaya.com

. 2015. Macam - macam tas. (29 Maret 2016)

www.nibroza.com

2013. Pengertian gaya desain Eklektik. (29 Maret 2016)

http://www.edupaint.com/warna/ragam-warna/4589-gaya-eklektik-penuh-estetika.html

2015. Situs jual beli aksesoris Skateboard reggae. (17Maret 2016)

http://www.zazzle.com/reggae+skateboards 